\title{
Assessing the Social and Environmental Costs of Institution Nitrogen Footprints
}

\author{
Jana E. Compton, ${ }^{1}$ Allison M. Leach, ${ }^{2}$ Elizabeth A. Castner, ${ }^{3}$ and James N. Galloway ${ }^{3}$
}

\begin{abstract}
This article estimates the damage costs associated with the institutional nitrogen (N) footprint and explores how this information could be used to create more sustainable institutions. Potential damages associated with the release of nitrogen oxides (NOx), ammonia $\left(\mathrm{NH}_{3}\right)$, and nitrous oxide $\left(\mathrm{N}_{2} \mathrm{O}\right)$ to air and release of nitrogen to water were estimated using existing values and a cost per unit of nitrogen approach. These damage cost values were then applied to two universities. Annual potential damage costs to human health, agriculture, and natural ecosystems associated with the N footprint of institutions were \$11.0 million (2014) at the University of Virginia (UVA) and \$3.04 million at the University of New Hampshire (UNH). Costs associated with the release of nitrogen oxides to human health, in particular the use of coal-derived energy, were the largest component of damage at UVA. At UNH the energy $N$ footprint is much lower because of a landfill cogeneration source, and thus the majority of damages were associated with food production. Annual damages associated with release of nitrogen from food production were very similar at the two universities ( $\$ 1.80$ million vs. $\$ 1.66$ million at UVA and UNH, respectively). These damages also have implications for the extent and scale at which the damages are felt. For example, impacts to human health from energy and transportation are generally larger near the power plants and roads, while impacts from food production can be distant from the campus. Making this information available to institutions and communities can improve their understanding of the damages associated with the different nitrogen forms and sources, and inform decisions about nitrogen reduction strategies.
\end{abstract}

Keywords: damage costs; nitrogen footprint; Nitrogen Footprint Tool; sustainability in higher education

\section{Introduction}

Human activities currently release reactive nitrogen (defined as all $\mathrm{N}$ species except $\mathrm{N}_{2}$ ) to the environment at rates that may be fourfold greater than the amount from natural terrestrial sources on Earth. ${ }^{1}$ This release comes from the loss of nitrogen to the environment beyond the intended use of producing food, fiber, energy, transportation, and materials. People and institutions may have a general idea of the benefits of using nitrogen to produce food and fiber, but there may be less general recognition of the impacts of reactive nitrogen. ${ }^{2}$ Release of nitrogen to air, land, and water has a host of effects on human health, ecosystems, and the economy, many of which scientists and economists are just beginning to develop methods to quantify. ${ }^{3,4}$ Accounting for this range of impacts provides key information for decision making about the different options for meeting society's demands for producing energy, food, and transportation.

'Western Ecology Division, US Environmental Protection Agency, Corvallis, Oregon.

2Department of Natural Resource \& the Environment, The Sustainability Institute, University of New Hampshire, Durham, New Hampshire.

${ }^{3}$ Department of Environmental Sciences, University of Virginia, Charlottesville, Virginia.

Published by Mary Ann Liebert, Inc. This Open Access article is distributed under the terms of the Creative Commons Attribution Noncommercial License (http://creativecommons.org/licenses/by-nc/4.0), which permits any noncommercial use, distribution, and reproduction in any medium, provided the original author(s) and the source are credited. 


\section{Background}

\section{Damage Costs for Nitrogen}

Nitrogen is often tracked by measuring the amount of nitrogen moving through the nitrogen cascade (Figure 1). However, the effects are not only related to the amount of nitrogen moving; the form, location, and mechanism of impact may be more important. In order to understand the broader connections to sustainability, more effort is needed to connect nitrogen release to the environment to the associated impacts on social and economic systems. Recent efforts have improved our ability to quantify the costs of nitrogen release to human health and ecosystems, but questions remain about how to use this information to inform decisions at the right scale. This could be seen as a multitiered issue: Some of this information can be used for national policy, state/city policies, and institutional policies.

Large-scale estimates of reactive nitrogen damage costs to human health, ecosystems, and the economy are in the hundreds of billions of dollars per year in the United States and E.U. ${ }^{3,4}$ Several types of costs arise from nitrogen release to the environment, including human mortality and morbidity costs, mitigation costs, and abatement costs. ${ }^{7}$ The most substantial benefits measured from U.S. Clean Air Act regulations are associated with reductions in mortality and illness associated with emissions of nitrogen oxides (NOx), a precursor to particulate matter and ozone formation. ${ }^{8}$ Nitrate is a contaminant that is regulated in drinking water because of its role in causing methemoglobinemia (blue baby syndrome in

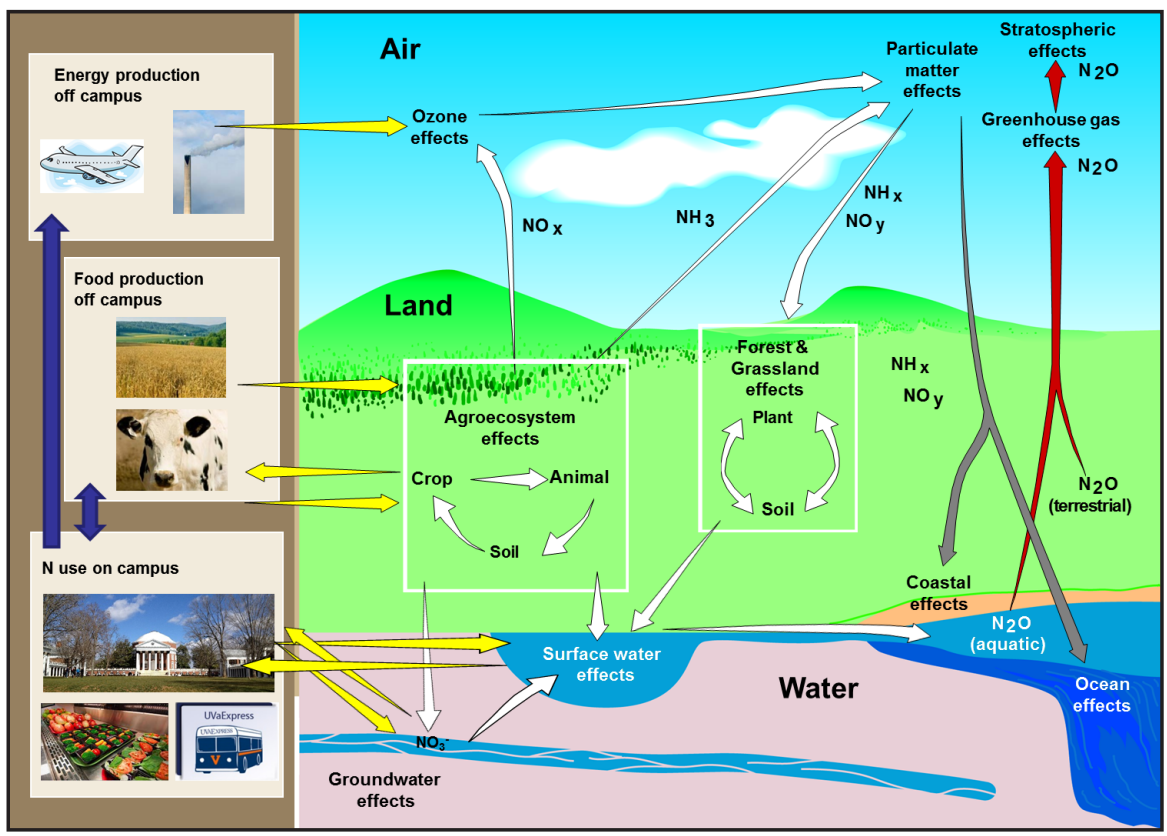

Figure 1. The nitrogen cascade for institutions: release of nitrogen from institutional $\mathrm{N}$ footprints and pathways through the environment. 5,6 Yellow arrows indicate inputs to the environment, white arrows are internal cycles, red arrows indicate $\mathrm{N}_{2} \mathrm{O}$ fluxes, grey arrows indicate particulate inputs, and blue arrows show transfers within the institution.

very young children), and also is linked to a number of other health issues such as increased risk of various types of cancer. ${ }^{9,10}$ Nitrate released to groundwater and surface waters from fertilizers or manure applied to agricultural fields may contaminate waters that are used for private or public drinking water supplies, requiring expensive treatment or replacement.

It is clear that there is great potential for damages when viewed at the national policy scale, but questions remain about how to use this information to inform more local decisions. Some of the research at regional scales has shown that the specific metrics chosen to illustrate these impacts are important. ${ }^{7,11}$ For example, in the Chesapeake Bay watershed, the largest nitrogen sources did not cause the greatest damages because of the importance placed on the effects of air pollutio on hu- man health. ${ }^{7}$ These studies point to the benefit of examining the impact of environmental pollution using multiple metrics including flux, damage costs, abatement costs, and mortality.

\section{Connecting Damage Costs to a N Footprint}

A nitrogen footprint is a metric that estimates the total reactive nitrogen released to the environment from a person, organization, or institution's resource consumption. ${ }^{12} \mathrm{~N}$ footprint tools have been developed for individual consumers ${ }^{12}$ and for institutions, such as colleges and universities. ${ }^{13}$ There are several reasons to examine the damage costs associated with the nitrogen footprint of institutions. In particular, knowledge about the social, economic, and environmental impacts of the $\mathrm{N}$ footprint of colleges and universities could help 
communicate to the community the broad consequences of choices at the individual and institutional level. Institutions are well positioned to use the damage cost results in decision making because they can set policies for an entire institution and could take damage costs into account for their nitrogen reduction plans.

This study builds upon the existing network of efforts to measure and manage the nitrogen footprints of institutions. ${ }^{14}$ The first step in this study was to apply an existing framework for connecting damage costs from nitrogen pollution to the $\mathrm{N}$ footprint concept. The current values that were used to estimate national and continental-scale damage assessments from the E.U. and United States were also used for this study. ${ }^{3,4}$ Next, case studies for the University of Virginia (UVA) and the University of New Hampshire (UNH) were undertaken to demonstrate how damages could be used as an educational tool and as a way to inform campus policies. These institutions were chosen because they were two of the first to estimate their $\mathrm{N}$ footprints, and they also use very different energy sources-coal at UVA and landfill cogeneration at UNH. These differences in energy sources are expected to have differential impacts on human respiratory health and possibly other damages. For both institutions, the amount of nitrogen released to the environment by different sectors was connected to the cascade of nitrogen impacts on human health, ecosystems, and the economy. A discussion of how damage costs could be used to communicate and reduce $\mathrm{N}$ footprints follows.

\section{Methods}

\section{N Footprint Estimates for UVA and UNH}

The Nitrogen Footprint Tool for institutions ${ }^{13}$ was used to calculate the $\mathrm{N}$ footprint for UVA and UNH in 2014. ${ }^{14}$ The University of Virginia is a public university in Charlottesville, Virginia. The full-time equivalent (FTE) number of people on the UVA campus is 35,894 , which includes a 2014 student population of 22,030 together with faculty and staff. In addition to core campus activities, UVA also has an on-site hospital, which is part of the energy and food needs of the campus. The University of New Hampshire is a public university in Durham, New Hampshire, with a 2014 FTE student population of 14,182 and, together with staff and faculty, a total of 16,548 FTE on campus.

The major areas of an institution's resource consumption that contribute to nitrogen pollution, including food purchases, food consumption/ sewage, utilities usage, transportation (both campus vehicles and commuting), research animals, and fertilizer application for the year 2014, are accounted for in the calculations. The food $\mathrm{N}$ footprint includes both the upstream nitrogen losses that occur during food production (calculated with virtual $\mathrm{N}$ factors, which constitute the mass of $\mathrm{N}$ released to the environment during food production per mass of $\mathrm{N}$ in food) as well as the downstream losses that occur after food is consumed and enters the sewage stream as human waste. ${ }^{13}$ Appropriate emission factors were used for different types of fuels for utilities and trans- port. ${ }^{13}$ Food consumption at both UVA and UNH was corrected for the amount of nitrogen removed or denitrified during sewage treatment. The $2014 \mathrm{~N}$ footprint data for each school is shown in the Supplementary Material, which may be found online at www.liebertpub.com/sus.

\section{Connecting Nitrogen Damage Costs with N Footprint}

Damage costs associated with specific nitrogen fluxes were obtained from an existing approach ${ }^{4}$ that presents the damage cost in dollars per kilogram of nitrogen released to the environment (Table 1). Many of the damage cost estimates were obtained from large-scale studies (national or regional in nature) and thus were not derived from specific studies in the school's boundaries. Some of the estimates are from a regional study of the Chesapeake Bay watershed, ${ }^{7}$ in which UVA is located. The cost values represent incremental or marginal increases in costs associated with the impacts of nitrogen use on a per-unit-of-nitrogen basis and assume a linear response function. Incorporation of spatially dependent cost estimates are just beginning to be recognized in the literature, ${ }^{15}$ and it is challenging to incorporate this cost of the virtual nitrogen release without knowing exactly where food was grown. The dollar per kilogram nitrogen values were adjusted for inflation into 2014 U.S. dollar equivalents using the consumer price index (multiplied by $\$ 1.10) .{ }^{16}$ All damage costs are in 2014 U.S. dollar equivalents to coincide with the 2014 institution N footprint data.

The per kilogram damage costs associated with nitrogen forms 


\begin{tabular}{|c|c|c|c|c|}
\hline Media & $\begin{array}{l}\text { Damage or benefit associated with } \\
\text { reactive } \mathrm{N} \text { form }\end{array}$ & $\begin{array}{l}\text { Sector where } \\
\text { impact occurs }\end{array}$ & $\begin{array}{c}\text { Cost } \\
(\$ / \mathbf{k g ~ N})\end{array}$ & References \\
\hline Air & $\begin{array}{l}\text { Human respiratory health }-\mathrm{NOx} \\
\text { Human respiratory health }-\mathrm{NH}_{3} \\
\text { Visibility - } \mathrm{NOx}, \mathrm{NH}_{3} \\
\text { Greenhouse gas damages }-\mathrm{N}_{2} \mathrm{O} \\
\text { Climate regulation benefit - } \mathrm{NOx}\end{array}$ & $\begin{array}{l}\text { Health/Social } \\
\text { Health/Social } \\
\text { Ecosystems } \\
\text { Climate } \\
\text { Climate }\end{array}$ & $\begin{array}{lr}\$ & 25.41 \\
\$ & 5.42 \\
\$ & 0.34 \\
\$ & 14.87 \\
\$ & (4.96)\end{array}$ & $\begin{array}{l}7 \\
7 \\
7 \\
4 \\
4\end{array}$ \\
\hline Land & $\begin{array}{l}\text { Damage to structures }-\mathrm{NOx}, \mathrm{NH}_{3} \\
\text { Ozone damage to crops - } \mathrm{N}_{2} \mathrm{O} \\
\mathrm{UV} \text { damage to crops - } \mathrm{N}_{2} \mathrm{O} \\
\text { Ozone damage to forests - } \mathrm{NOx} \\
\mathrm{N} \text { fertilization of forests - } \mathrm{NOx}, \mathrm{NH}_{3} \\
\text { Plant diversity declines - NOx, } \mathrm{NH}_{3}\end{array}$ & $\begin{array}{l}\text { Health/Social } \\
\text { Agriculture } \\
\text { Agriculture } \\
\text { Ecosystems } \\
\text { Ecosystems } \\
\text { Ecosystems }\end{array}$ & $\begin{array}{ll}\$ & 0.10 \\
\$ & 1.66 \\
\$ & 1.46 \\
\$ & 0.98 \\
\text { NE } \\
\$ & 8.50\end{array}$ & $\begin{array}{l}7 \\
7 \\
7 \\
5 \\
- \\
7\end{array}$ \\
\hline Water & $\begin{array}{l}\text { Closures by harmful algal blooms } \\
\text { Replacement with bottled water } \\
\text { Treatment of public drinking water } \\
\text { Treatment of private well water } \\
\text { Human health - nitrate } \\
\text { Lake waterfront property values } \\
\text { Recreational Freshwater use } \\
\text { Endangered species protection } \\
\text { Eutrophication }\end{array}$ & $\begin{array}{l}\text { Health/Social } \\
\text { Health/Social } \\
\text { Health/Social } \\
\text { Health/Social } \\
\text { Health/Social } \\
\text { Ecosystems } \\
\text { Ecosystems } \\
\text { Ecosystems } \\
\text { Ecosystems }\end{array}$ & \begin{tabular}{ll}
\multicolumn{2}{c}{$\mathrm{NE}$} \\
$\$$ & 0.15 \\
& $\mathrm{NE}$ \\
$\$$ & 0.59 \\
$\$$ & 1.94 \\
$\$$ & 0.23 \\
$\$$ & 0.19 \\
$\$$ & 0.01 \\
$\$$ & 17.70
\end{tabular} & $\begin{array}{c}17 \\
- \\
6 \\
4 \\
18 \\
18 \\
18 \\
4\end{array}$ \\
\hline
\end{tabular}

Values in parentheses represent benefits; costs are U.S. dollar equivalents of damage associated with one kilogram of $\mathrm{N}(\$ 2014)$. Values were rounded to the penny. NE, no estimate available.

released by UVA and UNH were calculated using the primary form and mode of impact as shown in Table 1, combined with the footprint data by form. (For all footprint data, see Appendix 1, which may be found online at www.liebertpub.com/sur.) Because the food $\mathrm{N}$ footprint is calculated as the total nitrogen loss, the total food $\mathrm{N}$ footprint was assigned to different nitrogen species based on national release rates shown in Figure 2. Virtual nitrogen from food production was apportioned ${ }^{19}$ into hydrologic nitrogen, ammonia, nitrogen oxides, storage, and denitrification, shown in Figure 2. The nitrogen release from all uses to different nitrogen forms was combined with the damage costs associated with those forms. The hydrologic nitrogen release to water was used to estimate the damages associated with release to surface water. Nitrogen was assumed to cascade to surface waters, groundwater, and coastal systems but given the scales of the university, only the surface water impacts were included in this study. The estimated storage and eventual release to atmospheric dinitrogen does not have a cost associated with it since it is not reactive and thus does not have direct effects or economic impacts.

\section{Results}

The estimates of total release of reactive nitrogen to the environment were $444,000 \mathrm{~kg} \mathrm{~N}$ at UVA, and $186,000 \mathrm{~kg} \mathrm{~N}$ at UNH for the year 2014 (Figure 3a). ${ }^{14}$ Utilities were the most important sector for UVA, representing 52 percent of the total $\mathrm{N}$ footprint; food production represented 34 percent (Figure 3a). At UVA, transportation was 8 percent and research animals were another 5 percent, while both fertilizer and food consumption and waste were each less than 1 percent. In contrast, UNH's footprint was dominated by food production $(73 \%$ of the total $\mathrm{N}$ footprint), with transportation at 13 percent and utilities at 8 percent. Food consumption was 4 percent and research animals less than 1 percent of the total $\mathrm{N}$ footprint.

Estimated damage costs to human health, agriculture, and ecosystems

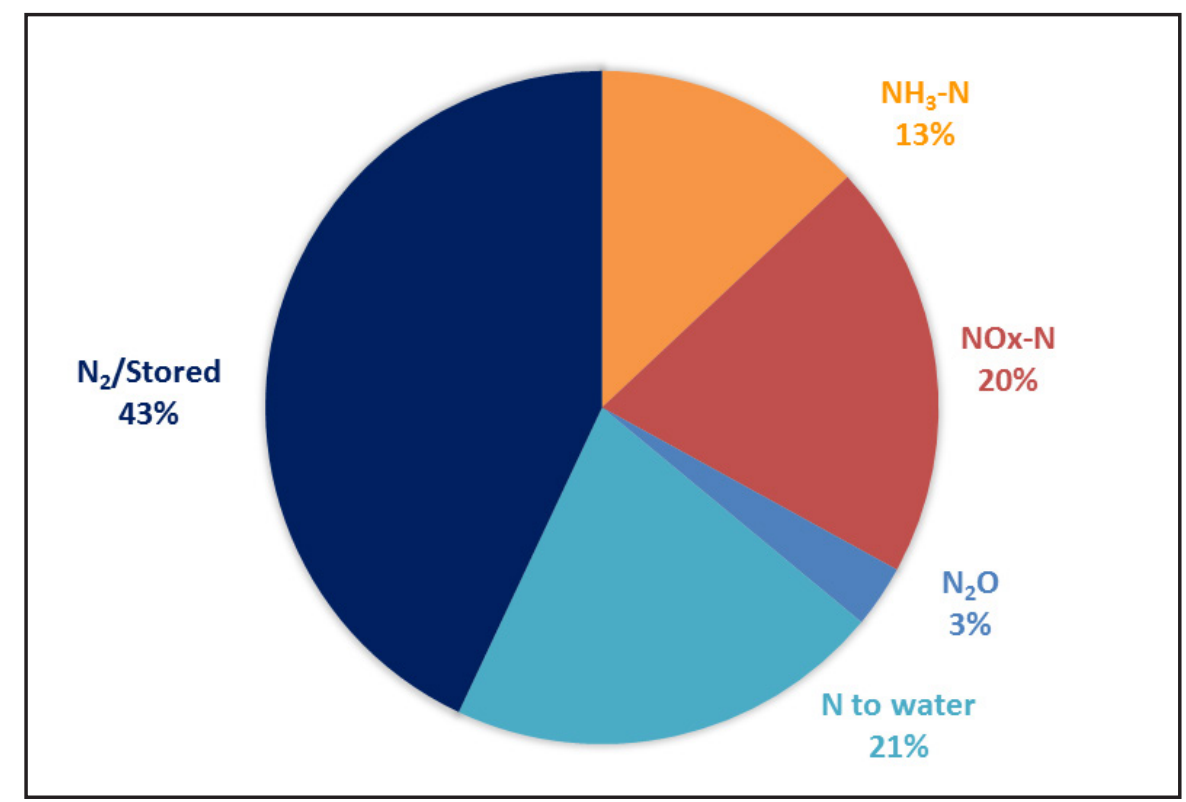

Figure 2. Assumed fates of $\mathrm{N}$ released to the environment from food production. ${ }^{19}$ 


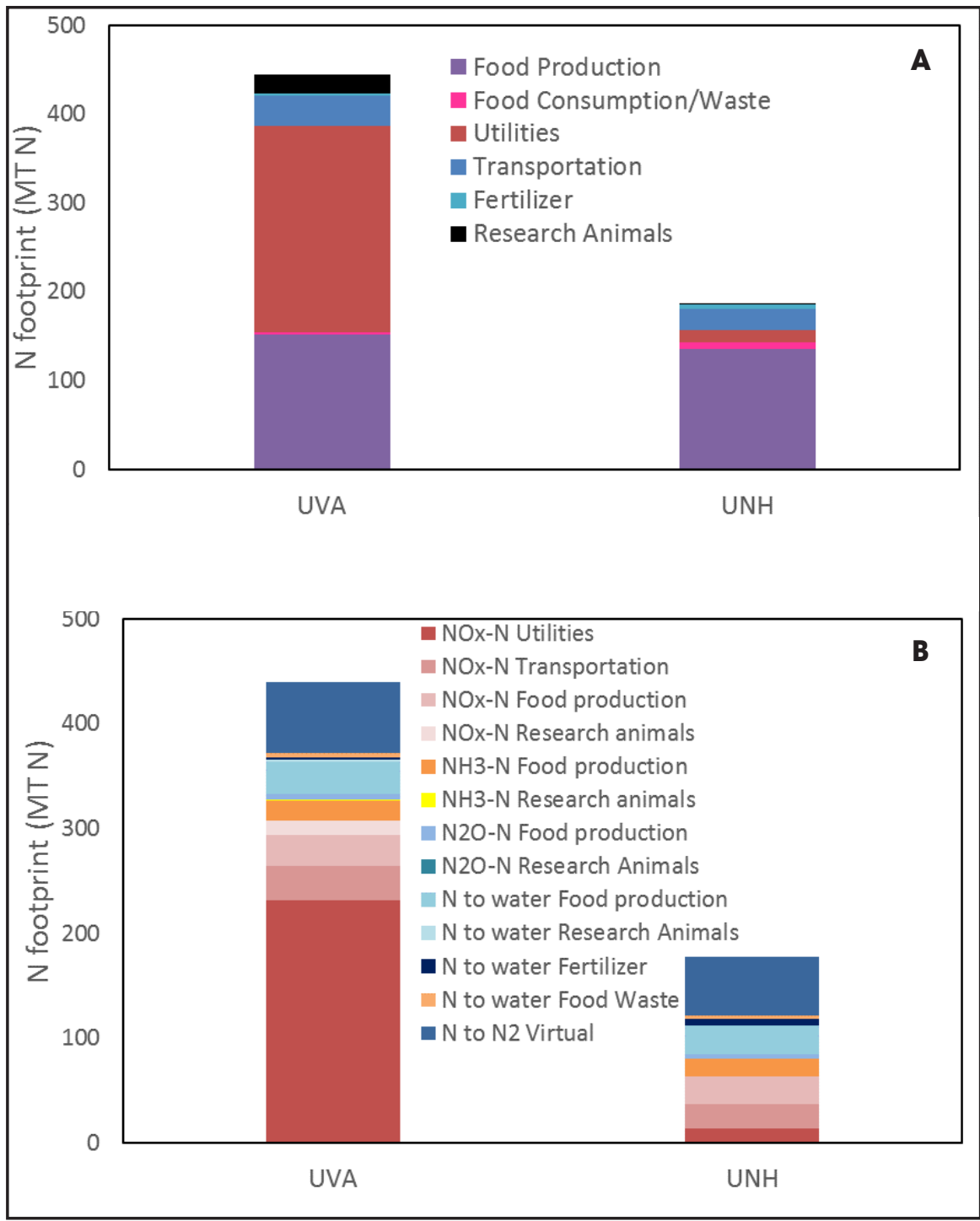

Figure 3. Nitrogen release: A) by source, and B) by N form; from the University of Virginia (UVA) and University of New Hampshire (UNH), 2014.

associated with the $\mathrm{N}$ footprint of institutions were (U.S.) \$11.0 million 2014 at UVA and (U.S.) \$3.04 million 2014 at UNH (Table 2). Costs associated with the effects of nitrogen oxides on human respiratory health were the largest component of damage at UVA ( $\$ 9.83$ million; Figure 3). The utilities sector was responsible for the largest component of this damage at $\$ 7.43$ million. At UNH the nitrogen impact for utilities is much lower ( $\$ 0.44$ million) because of the cogeneration energy source releases little $\mathrm{N}$ (methane gas from a local landfill), and thus the largest proportion of damages were associated with nitrogen release from food production. These estimates are incomplete because the full range of damage costs are not yet available for some potential impacts due to a lack of information about, for example, drinking water costs and effects of harmful algal blooms (see Discussion).

Food production is the next largest sector influencing damage costs and had only a slightly higher result at UVA (\$1.86 million) than UNH ( $\$ 1.66$ million), although the FTE population is much larger at UVA. This difference is in part explained by the greater number of meals served per year at UNH (3.0 million at UNH vs. 1.8 million at UVA). The mass of food served is another good comparison metric: UVA served 135 tons of nitrogen in food and UNH served 148 tons of nitrogen in food, ${ }^{14}$ similar to the pattern in overall food production damages. The overall annual damages associated with nitrogen-related resource use by each community member is \$304 per capita at UVA and \$184 per capita at UNH.

The damages and benefits associated with each institution's footprint were quantified by the sector releasing the reactive nitrogen (Figure $4 \mathrm{a}$ ) and the sector where the damages occur (Figure $4 \mathrm{~b}$ ). The climate benefits occur from the role that particulates play in cooling the atmosphere, and this benefit increases with emissions of nitrogen oxides and ammonia which can form particulates (shown as a negative damage in Figure $4 \mathrm{~b}$ ). However, in total these forms have a greater negative effect on human respiratory health via hospital visits and mortality, and accordingly, that is where the largest damage costs are observed. Clearly, the utilities footprint causes the largest impacts at UVA, which have important human health and social impacts via the effects on respiratory health. The effects on agriculture are relatively small. The second largest impacts are to ecosystems, primarily through eutrophication, where the main impact is a reduction in biodiversity and changes in the structure and function of terrestrial and freshwater ecosystems, which in turn can hamper recreation and impact drinking water supplies. 


\section{Discussion}

Sustainability of human institutions like colleges and universities can be improved by better balancing the demands for food, energy, and materials with the broader social and environmental costs of meeting these demands. The damage costs can provide insights that may not be reflected in the nitrogen fluxes alone. While the UVA $\mathrm{N}$ footprint was 2.4 times greater than the $\mathrm{UNH}$ $\mathrm{N}$ footprint, the damage costs associated with the UVA $\mathrm{N}$ footprint were 3.6 times greater than for UNH (Figure 3 vs. Figure 4). This greater cost at UVA is seen because the utilities $\mathrm{N}$ footprint (and therefore the $\mathrm{NOx}$ and $\mathrm{N}_{2} \mathrm{O}$ losses) makes up a much larger percentage of the UVA footprint.

The types of damages are also important. The UVA damages associated with human health are 74 percent of the damage costs but only 64 percent of the nitrogen flux, due to the high value placed on human health impacts associated with nitrogen oxides (NOx) (Figure 4).

As do many institutions and communities in the mid-Appalachian region, UVA derives much of its energy from coal-fired power plants, which results in a substantial release of nitrogen to the environment. There has been a general declining trend in the percentage of energy derived from coal since the late 1980s at UVA. ${ }^{20}$ For example, the percentage of coal use decreased from 74 percent in 2010 to 42 percent in 2014 in favor of natural gas, ${ }^{20}$ and this decline may have decreased impacts related to nitrogen oxides on human health over this timeframe. $\mathrm{UNH}$ acquires most of the energy to heat and power its campus from

Table 2. Total Damage Costs in 2014 U.S. Dollar Equivalents Associated with the $\mathrm{N}$ footprint at the University of Virginia (UVA) and the University of New Hampshire (UNH)

\begin{tabular}{|c|c|c|c|c|c|}
\hline $\mathrm{N}$ form released & \$ per kg N & & UVA & & UNH \\
\hline NOx-N Utilities & $\$ 32.00$ & $\$$ & $7,430,000$ & $\$$ & 444,000 \\
\hline NOx-N Transportation & $\$ 32.00$ & $\$$ & $1,030,000$ & $\$$ & 743,000 \\
\hline NOx-N Food production & $\$ 32.00$ & $\$$ & 950,000 & $\$$ & 848,000 \\
\hline NOx-N Research animals & $\$ 32.00$ & $\$$ & 457,000 & $\$$ & 621 \\
\hline $\mathrm{NH}_{3}-\mathrm{N}$ Food production & $\$ 10.40$ & $\$$ & 198,000 & $\$$ & 178,000 \\
\hline $\mathrm{NH}_{3}-\mathrm{N}$ Research animals & $\$ 10.40$ & $\$$ & 12,600 & $\$$ & 16 \\
\hline $\mathrm{N}_{2} \mathrm{O}-\mathrm{N}$ Food production & $\$ 17.80$ & $\$$ & 72,000 & $\$$ & 64,700 \\
\hline $\mathrm{N}_{2} \mathrm{O}-\mathrm{N}$ Research animals & $\$ 17.80$ & $\$$ & 4,600 & $\$$ & 6 \\
\hline $\mathrm{N}$ to water Food production & $\$ 20.70$ & $\$$ & 637,000 & $\$$ & 571,000 \\
\hline $\mathrm{N}$ to water Research animals & $\$ 20.70$ & $\$$ & 40,481 & $\$$ & 52 \\
\hline $\mathrm{N}$ to water Fertilizer & $\$ 20.70$ & $\$$ & 37,900 & $\$$ & 123,000 \\
\hline $\mathrm{N}$ to water Food waste & $\$ 20.70$ & $\$$ & 106,000 & $\$$ & 67,900 \\
\hline All NOx-N damages & & $\$$ & $9,860,000$ & $\$$ & $2,040,000$ \\
\hline All Food production damages & & $\$$ & $1,860,000$ & $\$$ & $1,660,000$ \\
\hline Total damages & & $\$$ & $11,000,000$ & $\$$ & $3,040,000$ \\
\hline
\end{tabular}

Values rounded to 3 significant digits or to the dollar.

its on-campus cogeneration plant, which uses processed methane gas from a landfill in nearby in Rochester, New Hampshire. The landfill gas has a much lower nitrogen release to the environment per unit of energy generated than coal. ${ }^{21}$

In addition to the intentional benefits to food, fiber, and energy production from nitrogen use, release of nitrogen to the environment may also have some unintentional benefits. For example, cooling can result from particulate formation and reflection of heat away from Earth's atmosphere (Table 1; Figure 4). However particulate matter also has negative effects on human health. The climate benefits were relatively small in the current study (see Table 1 for nitrogen-specific values), and some other economic values at present are not sufficiently well documented to include in this analysis, such as possible stimulation of carbon storage by nitrogen deposition in forests.

Some kinds of damages do not have associated per kilogram costs, and thus cannot be connected to the $\mathrm{N}$ footprint of these effects at this time (Table 1). For example, nitrogen, along with phosphorus, plays a role in the formation of harmful cyanobacterial algal blooms (HABs) in freshwater and coastal ecosystems, which in turn cause beach closures, health effects on pets and wildlife, and in some cases, closures of drinking water supplies. ${ }^{22}$ The Center for Disease Control recently established a reporting system for $\mathrm{HAB}$ events, ${ }^{23}$ which represents an important step in improving our tracking for the United States. Both HABs and increased nitrate in drinking water supplies are rising in importance, and may be increasing the treatment 
and replacement costs associated with nutrient pollution in private and public water supplies. Considering that neither groundwater nor coastal impacts were incorporated into this assessment, and that numerous known impacts are not suitably characterized economically for incorporation, the damage assessment seems likely to be a conservative estimate.

\section{How Can We Use the Information about the Costs of Nitrogen Release to Inform Decisions?}

Nitrogen use can be managed at a variety of scales. For example, farmers have a good deal of control over the amount of nitrogen they apply to their fields. Policies can influence emissions standards for automobiles or for the amount of nitrogen released from power or sewage treatment plants. And individuals can have an influence on their nitrogen use through choices about diet or transportation. ${ }^{12}$ The scales and extent of these impacts can be very different. Some are felt at the source, such as near-roadway emissions of nitrogen oxides from cars; others are felt from afar. For example, to produce a hamburger that is ultimately consumed in Virginia, the nitrogen used in production might leach from corn fields and feedlots in the Midwest and move into soils, groundwater, streams, rivers, and coastal waters of the Midwest and the Gulf of Mexico. Thus it is important to consider not only the food consumption impacts, but also incorporate the much larger, albeit distant, food production impacts because they affect human health, the economy, and ecosystems in those locations.

Damage costs help put the $\mathrm{N}$ footprint into perspective and into

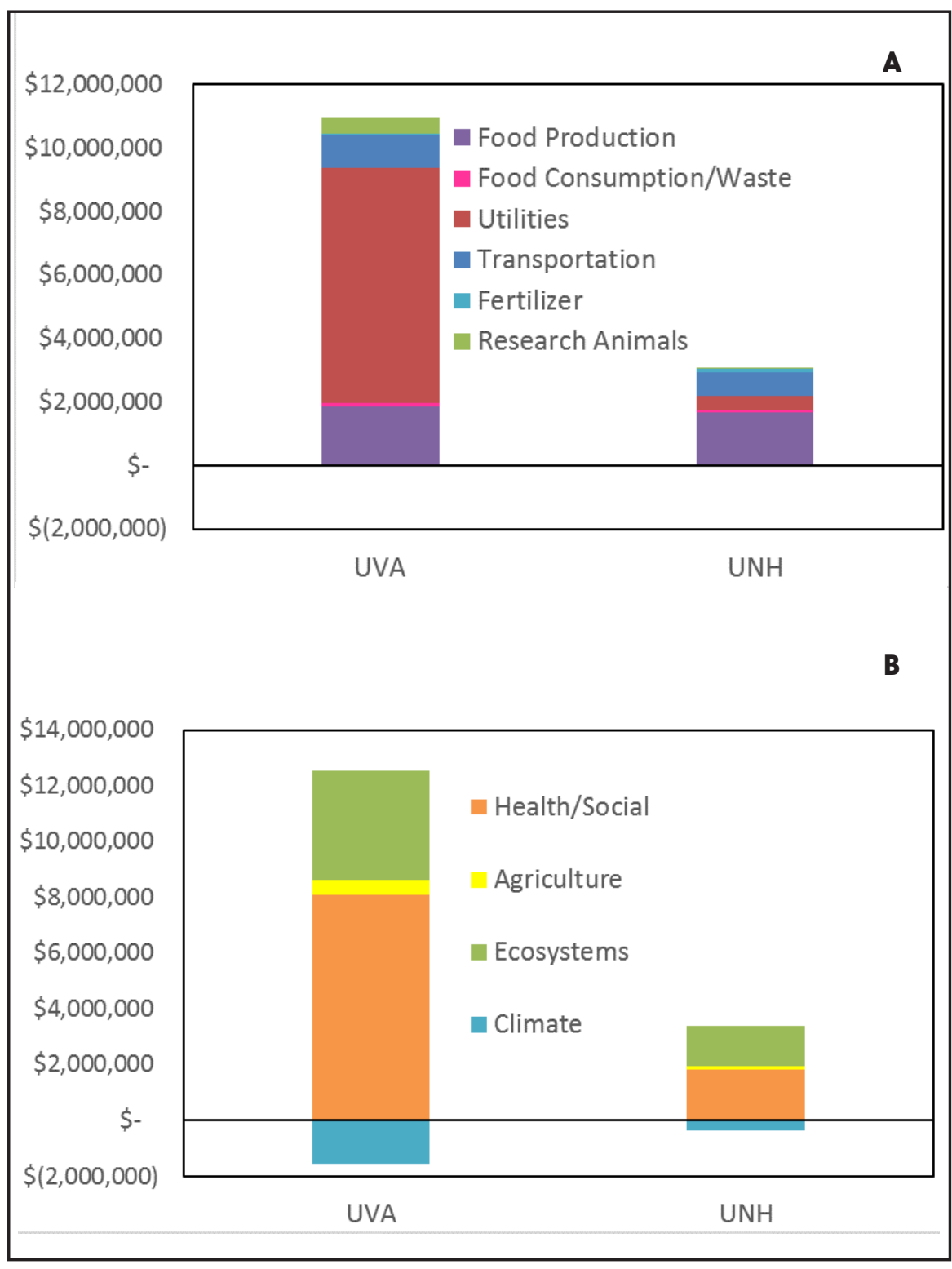

Figure 4. Damage costs (2014) associated with $\mathbf{A}$ ) the sector releasing the $\mathrm{N}$ by institution and $\mathbf{B}$ ) the sector where the damages occur based on the categories in Table 1. Negative values represent the economic benefits of climate cooling from particulates.

terms that may be more meaningful than the mass of nitrogen released (e.g., kilograms). This data could be especially useful in communicating damages related to an institution's local environment, which may be a higher priority for the institution to minimize. It can either choose to reduce its $\mathrm{N}$ footprint currently, or face the possibility of the future need to pay significantly higher damage costs to repair their local environ- ment. An important step will be to ground truth these estimates for particular locations and determine whether these values are appropriate for study at institutions. Another step might be to quantify the cost to implement $\mathrm{N}$ footprint management and nitrogen reduction strategies. Assessing reduction scenario damage costs would add value to management plans and $\mathrm{N}$ footprint reduction goals. 
Combining the carbon and nitrogen footprints could better position individuals and institutions to make choices about food, transportation, and energy use. The nitrogen footprint tool is being integrated into the Campus Carbon Calculator ${ }^{\text {rux }}$ so that institutions can track and manage their carbon and nitrogen footprints together. ${ }^{24}$ The social cost of carbon is somewhat simpler to assess in practice because once released, a molecule of carbon dioxide moves into the atmosphere and all molecules have an equal role in influencing the climate, regardless of where they originate. The social cost of nitrogen is much more complex to assess because of the different forms, flows, fates, and effects of nitrogen..$^{15}$ In contrast, nitrogen costs could be viewed as more locally tangible and measurable than carbon costs, in particular the human health impacts and some of the drinking water and eutrophication effects, and thus may connect to benefits that directly matter to students and institutions.

The information about damage costs could be used in an educational setting to provide students the opportunity to see the potential benefits of making reductions to their food, transportation, and energy use. In addition, making this information available to institutions or other types of communities can improve their understanding of the damages associated with the different nitrogen forms and sources, and, in turn, inform their decisions about their nitrogen reduction strategies.

\section{Acknowledgments}

The authors would like to thank Matt Heberling and Anna Perry for helpful feedback that improved this article. The views expressed in this article are those of the authors and do not necessarily reflect the views or policies of the U.S. Environmental Protection Agency.

\section{Author Disclosure Statement}

No competing financial interests exist.

\section{References}

1. Galloway JN, Theis TL, and Doering OC. Managing nitrogen pollution in the United States. EM Magazine. Air and Waste Management Association, September 15, 2015, pp. 6-11.

2. Resource Media. Nitrogen in the News: Message tips and best practices for researchers and communications staff. Resource Media. 2014. http://www.resource-media. org/wp-content/uploads/2014/08/ NitrogenCommsTipsheet_RM.pdf (last accessed 3/17/2017).

3. Sobota DJ, Compton JE, McCrackin ML, et al. Cost of reactive nitrogen release from human activities to the environment in the United States. Environ Res Lett 2015;10:025006.

4. van Grinsven HJ, Holland M, Jacobsen $\mathrm{BH}$, et al. Costs and benefits of nitrogen for Europe and implications for mitigation. Environ Sci Technol 2013;47(8):3571-3579.

5. Galloway JN, Aber JD, Erisman JW, et al. The nitrogen cascade. Bioscience 2003;53:341-356.

6. Compton JE, Harrison JA, Dennis RL, et al. Ecosystem services altered by human changes in the nitrogen cycle: A new perspective for US decision making. Ecol Lett 2011;14:804-815.

7. Birch MB, Gramig BM, Moomaw WR, et al. Why metrics matter: Evaluating policy choices for reac- tive nitrogen in the Chesapeake Bay watershed. Environ Sci Technol 2010;45:168-174.

8. Chestnut LG, and Mills DM. A fresh look at the benefits and costs of the U.S. acid rain program. J Environ Manage 2005;77:252-266.

9. Townsend AR, Howarth RW, Bazzaz FA, et al. Human health effects of a changing global nitrogen cycle. Front Ecol Environ 2003;1:240-246. 10. van Grinsven HJ, Rabl A, and de Kok TM. Estimation of incidence and social cost of colon cancer due to nitrate in drinking water in the EU: A tentative cost-benefit assessment. Environ Health 2010;9:1.

11. Horowitz AI, Moomaw WR, Liptzin D, et al. A multiple metrics approach to prioritizing strategies for measuring and managing reactive nitrogen in the San Joaquin Valley of California. Environ Res Lett 2016;11:064011.

12. Leach AM, Galloway JN, Bleeker A, et al. A nitrogen footprint model to help consumers understand their role in nitrogen losses to the environment. Environ Dev 2012;1:4066.

13. Leach AM, Majidi AN, Galloway JN, et al. Toward institutional sustainability: A nitrogen footprint model for a university. Sus J Record 2013;6:211-219.

14. Castner EA, Leach AM, Compton JW, et al. Comparing institution nitrogen footprints: metrics for assessing and tracking environmental impact. Sus J Record 2017;10:105113.

15. Keeler BL, Gourevitch JD, Polasky S, et al. The social costs of nitrogen. Sci Adv 2016;2:e1600219.

16. Consumer Price Index Inflation Calculator. Bureau of Labor Statistics. http://data.bls.gov/cgi-bin/cpicalc.pl (last accessed 3/17/2017).

17. Kusiima JM and Powers SE. Monetary value of the environmen- 
tal and health externalities associated with production of ethanol from biomass feedstocks. Energy policy 2010;38:2785-2796.

18. Dodds WK, Bouska WW, Eitzmann JL, et al. Eutrophication of US freshwaters: Analysis of potential economic damages. Environ Sci Tech 2008;43:12-19.

19. Houlton BZ, Boyer E, Finzi A, et al. Intentional versus unintentional nitrogen use in the United States: Trends, efficiency and implications. Biogeochemistry 2013;114:11-20. 20. University of Virginia. Operations Annual Report 2015. University of Virginia Facilities Management.
2015. https://www.fm.virginia.edu/ docs/annualreports/2015/FMOperationsAnnualReport2015.pdf (last accessed 3/17/2017).

21. University of New Hampshire Sustainability Institute. Cogeneration \& EcoLine (Landfill Gas). http:// www.sustainableunh.unh.edu/ecoline (last accessed 3/17/2017).

22. Brooks BW, Lazorchak JM, Howard MD, et al. Are harmful algal blooms becoming the greatest inland water quality threat to public health and aquatic ecosystems? Environ Toxicol Chem 2016;35:6-13. 23. Center for Disease Control and Prevention. One Health Harmful
Algal Bloom System (OHHABS). http://www.cdc.gov/habs/ohhabs. html (last accessed 3/172017).

24. Leach AM, Galloway JN, Castner E, et al. An integrated tool for calculating and reducing institution carbon and nitrogen footprints. Sus J Record 2017;10:140-148 .

Address correspondence to: Jana E. Compton Western Ecology Division US Environmental Protection Agency Corvallis, OR 97330

E-mail: Compton.jana@epa.gov 